\title{
Role of Laparoscopic Fundoplication in the Management of Gastroesophageal Reflux Disease- A Retrospective Study
}

\section{ABSTRACT}

Introduction: Gastroesophageal Reflux Disease (GERD) is a common gastrointestinal disease affecting 3-7\% of Asians and becoming a major healthcare burden in elderly population. Surgical intervention with laparoscopic fundoplication is the effective tool in the management of GERD.

Aim: To evaluate the role and advantages of laparoscopic fundoplication in the management of cases with GERD and to compare the laparoscopic nissen's fundoplication and laparoscopic toupet's fundoplication in management of GERD.

Materials and Methods: The present retrospective and prospective study was conducted in the Department of General surgery at Government Medical College, Nizamabad from August 2019 to July 2021. A total of 36 cases of both sexes, clinically diagnosed as chronic GERD undergone laparoscopic Nissen's fundoplication and laparoscopic toupet's fundoplication surgery were recruited. Preoperative and postoperative assessment of disease status was done at the end of third month and sixth month. Collected data was analysed by using Statistical Package for Social Sciences (SPSS) version 16.0. The chi-square test was used to test the significance of qualitative data. The The $p$-value $<0.05$ was considered as statistically significant.
Results: In total data collected for 36 cases, majority cases were between $31-40$ years $(n=13)$ and $41-50$ years $(n=11)$. Total of 19 patients had undergone laparoscopic nissen's fundoplication while 17 patients were of laparoscopic toupet's fundoplication surgery. The mean difference of age was statistically not significant $(p>0.05)$. Postsurgical significant improvement was observed in cases of grade $3(n=7)$, grade $4(n=19)$ and grade 5 $(n=10)$ oesophagitis. The mean duration to start oral liquids was 1.29 days and 1.08 days, mean duration of surgery was 3.62 hours and 3.19 hours, mean duration of hospital stay was 4.12 and 3.67 days and the average ambulatory period was 1.46 and 1.62 days in laparoscopic nissen's group and laparoscopic toupet's group, respectively.

Conclusion: The laparoscopic toupet's fundoplication and laparoscopic nissen's fundoplication were comparable in the management of postoperative complications. The incidence of postoperative dysphagia was comparatively more in laparoscopic Nissen's group than laparoscopic toupet's group. However, the incidence was diminished within six months of postoperative follow-up.

\section{INTRODUCTION}

The GERD is frequently under diagnosed and is a common cause of morbidity and mortality in elderly cases [1,2]. The prevalence of GERD was approximately $20 \%$ of adults in Western culture and $18.1 \%$ to $27.8 \%$ in US [3]. In India, the prevalence of GERD was $7.6 \%$ to $30 \%$ [4]. The GERD occur when the gastric content refluxes into the oesophagus and develops a spectrum of typical symptoms like heartburn, dysphagia, regurgitation and blenching and atypical symptoms like chest pain, hoarseness of voice, laryngitis, wheezing, cough, dental complications, aspiration pneumonia and asthma [3].

The successful outcome of surgery depends on the proper patient selection with typical and atypical symptoms. Complete lifestyle change and prolonged therapy are the first line treatment choice for the management of GERD. Besides this, laparoscopic fundoplication is the standard surgical treatment option for GERD [5]. Laparoscopic total or nissen's fundoplication (3600) is commonly performed anti-reflux operation for the management of severe GERD [6,7]. However, postsurgical complications like dysphagia and gas bloating have been reported [8,9]. Laparoscopic toupet's fundoplication or partial fundoplication $\left(270^{\circ}\right)$ had similar control of reflux and is associated with fewer incidences of postoperative complications [10]. The important goals of laparoscopic fundoplication is to improve quality of life, relieving patient from complications and relieving from GERD symptoms. A study by Chrysos $\mathrm{E}$ et al., reported that both techniques were equally effective and comparable in the management of GERD [11]. A study by Qin M et al., reported diverse outcome between both techniques [12]. In order to recommend the better antireflux surgery which results better postoperative outcome in this departmental setup, the present study was designed to evaluate the role and advantages of laparoscopic fundoplication in the management of cases with GERD.

\section{MATERIALS AND METHODS}

This retrospective and prospective study was conducted in the Department of General surgery at Government Medical College and Hospital, Nizamabad, Telangana, India, from August 2019 to July 2021. The retrospective data was collected from August 2019 to March 2020 and prospective data was collected from July 2020 to July 2021. The study protocol was approved by Institutional Ethics Committee of Government Medical College, Nizamabad (No. GMCH/IRB-IEC/2019/Jun/18P).

Inclusion criteria: Cases aged between 25 to 65 years, refractory to treatment, with clinical reflux symptoms, Barrett's oesophagus, with chest pain, chronic cough and asthma were included. 
Exclusion criteria: Cases with history of previous oesophageal surgery and short oesophagus, ulcers were excluded.

All the patients who undergone laparoscopic nissen's and laparoscopic toupet's fundoplication between August 2019 to July 2021 in the Department of General Surgery were included as sample size.

Patient's data was collected from medical records. A total of 36 cases of both sexes, clinically diagnosed by General Surgeon as chronic GERD undergone laparoscopic nissen's fundoplication $(n=19)$ and laparoscopic toupet's fundoplication $(n=17)$ surgery were recruited [6]. The above procedure was chosen with the investigator and departmental interest.

\section{Procedure}

All the study participants were subjected to detailed clinical and radiological examination preoperatively and postoperatively. The oesophagoscopy was used to assess the severity of oesophagitis pre and postoperatively after obtaining the patient's informed consent.

Preoperative barium swallow was performed in cases complained with dysphagia. The preoperative and postoperative status at third and sixth month of symptoms such as cough, hoarseness, asthma, chest pain was evaluated. Preoperative and postoperative symptoms like heartburn, dysphagia and regurgitation were checked by DeMeester scoring system. The DeMeester scoring system is commonly used scoring system for acid reflux. This is the scoring system to measure oesophageal acid exposure based on 24 hours pH scoring [13]. The severity of oesophagitis was evaluated by upper Gl endoscopy and the severity grading was assessed by New Savary-Millers grading system [Table/Fig-1] [14].

\begin{tabular}{|l|c|}
\hline Grade & Lesions \\
\hline 1 & Single erosive \\
\hline 2 & Multiple erosive \\
\hline 3 & Circumferential erosive \\
\hline 4 & Chronic lesions \\
\hline 5 & Non circular, star shaped \\
\hline [Table/Fig-1]: New Savary-Millers grading system.
\end{tabular}

The parameters like duration of surgery, duration of hospital stay, average ambulation period and time to start the oral liquids were noted. Details of pre and postoperative usage of medication was recorded. Postoperative assessment of oesophagitis was performed by oesophagoscopy. Postoperative assessment of disease status was done at the end of third month and sixth month. Postoperative clinical examination and repeat UGI endoscopy was done for all the cases.

\section{STATISTICAL ANALYSIS}

Extracted data was statistically analysed by using Statistical Package for Social Sciences (SPSS) version 16.0. The chi-square test was used to test the significance of qualitative data. The $p$-value $<0.05$ was considered as statistically significant.

\section{RESULTS}

Among 36 cases, majority cases were between 31-40 and 41-50 years [Table/Fig-2]. The mean difference was statistically not significant. The better improvement was observed in the grades of oesophagitis after surgery. All the cases in grade 3 , grade 4 and grade 5 before surgery showed improvement after surgery [Table/Fig-3].

\begin{tabular}{|c|c|c|c|c|c|}
\hline \multirow{2}{*}{$\begin{array}{l}\text { Age } \\
\text { and sex } \\
\text { (years) }\end{array}$} & \multicolumn{2}{|c|}{$\begin{array}{l}\text { Laparoscopic nissen's } \\
\qquad(n=19)\end{array}$} & \multicolumn{2}{|c|}{$\begin{array}{l}\text { Laparoscopic toupet's } \\
\qquad(n=17)\end{array}$} & \multirow[b]{2}{*}{$p$-value } \\
\hline & Male & Female & Male & Female & \\
\hline $25-30$ & 02 (10.52\%) & 01 (5.26\%) & 01 (5.88\%) & - & \multirow{5}{*}{0.269} \\
\hline $31-40$ & 04 (21.05\%) & 02 (10.52\%) & 04 (23.52\%) & 03 (17.64\%) & \\
\hline $41-50$ & 03 (17.5\%) & 03 (17.5\%) & 03 (17.64\%) & 02 (11.7\%) & \\
\hline $51-60$ & 01 (5.26\%) & 01 (5.26\%) & 01 (5.88\%) & 01 (5.88\%) & \\
\hline Above 60 & 01 (5.26\%) & 01 (5.26\%) & 01 (5.88\%) & 01 (5.88\%) & \\
\hline
\end{tabular}

\begin{tabular}{l|c|c|c|}
\hline Grade & Preoperative & At $3^{\text {rd }}$ month & At 6 $6^{\text {th }}$ month \\
\hline Grade 1 & - & $22(61.11 \%)$ & $35(97.22 \%)$ \\
\hline Grade 2 & - & $14(38.89 \%)$ & $01(2.77 \%)$ \\
\hline Grade 3 & $07(19.40 \%)$ & - & - \\
\hline Grade 4 & $19(52.70 \%)$ & - & - \\
\hline Grade 5 & $10(27.70 \%)$ & - & - \\
\hline
\end{tabular}

There was a significant improvement in the different grades of heartburn, dysphagia, regurgitation and epigastric pain at the sixth month of follow-up $(p<0.05)$ [Table/Fig-4]. The preoperative and postoperative assessment of hoarseness, and chest pain showed significant improvement at sixth month follow-up ( $p<0.05)$ [Table/Fig-5]. Intraoperative complications like herniation and pneumothorax was observed in two cases each. The mean duration to start medication of oral liquids was 1.29 days, mean duration of surgery was 3.62 hours and the average ambulation period of stay was 1.46 days for laparoscopic nissen's fundoplication [Table/Fig-6]. The postoperative assessment for incidence of dysphagia showed improvement at third month and sixth month follow-up. Laparoscopic toupet's group showed better improvement than laparoscopic nissen's fundoplication [Table/Fig-7]. The development of persistent dysphagia immediately after surgical procedure is leading cause of procedure failure. With this reason, this study was focused more on dysphagia.

\section{DISCUSSION}

The mean difference of age was statistically not significant ( $p$-value= 0.269) [Table/Fig-2]. The significant postoperative improvement was observed in the grades of oesophagitis. Preoperatively, all the cases were in grade $3(19.4 \%)$, grade 4 (52.7\%) and grade $5(27.7 \%)$ oesophagitis and showed significant improvements after surgery. Cases were completely relieved from preoperative heart burn, regurgitation and epigastric pain at six months after surgical procedure. Preoperatively, 15 cases had various grades of dysphagia and at the end of sixth month, 34 cases were relieved from dysphagia.

\begin{tabular}{|c|c|c|c|c|c|c|c|c|c|c|c|c|c|}
\hline \multirow[b]{2}{*}{ Symptoms } & \multicolumn{4}{|c|}{ Preoperative } & \multicolumn{4}{|c|}{ At $3^{\text {rd }}$ month } & \multicolumn{4}{|c|}{ At $6^{\text {th }}$ month } & \multirow[b]{2}{*}{$\mathrm{p}$-value } \\
\hline & Go & G1 & G2 & G3 & Go & G1 & G2 & G3 & Go & G1 & G2 & G3 & \\
\hline Heartburn & - & - & 20 & 16 & 27 & 09 & - & - & 36 & - & - & - & 0.042 \\
\hline Dysphagia & 21 & 07 & 05 & 03 & 31 & 03 & 02 & - & 34 & 01 & 01 & - & 0.002 \\
\hline Regurgitation & - & 7 & 20 & 09 & 31 & 05 & - & - & 34 & 02 & - & - & 0.002 \\
\hline Epigastric pain & 23 & 04 & 05 & 04 & 28 & 08 & - & - & 35 & 01 & - & - & 0.001 \\
\hline
\end{tabular}




\begin{tabular}{|l|c|c|c|c|c|c|c|}
\hline & \multicolumn{2}{|c|}{ Preoperative } & \multicolumn{2}{|c|}{ At $3^{\text {rd }}$ month } & \multicolumn{2}{c|}{ At $6^{\text {th }}$ month } & \multirow{2}{p-}{} \\
\cline { 2 - 7 } Symptoms & Present & Absent & Present & Absent & Present & Absent & value \\
\hline Cough & 08 & 28 & 04 & 32 & 01 & 35 & 0.238 \\
\hline Hoarseness & 3 & 33 & 01 & 35 & - & 36 & 0.026 \\
\hline Chest pain & 12 & 24 & 02 & 34 & - & 36 & 0.003 \\
\hline Asthma & 07 & 29 & 05 & 31 & 01 & 35 & 0.582 \\
\hline
\end{tabular}

[Table/Fig-5]: Pre and postoperative assessment of symptoms in study participants. The $p$-value $<0.05$ was considered as statistically significant.

\begin{tabular}{|l|c|c|}
\hline Parameters & $\begin{array}{c}\text { Laparoscopic nissen's } \\
\text { fundoplication }\end{array}$ & $\begin{array}{c}\text { Laparoscopic toupet's } \\
\text { fundoplication }\end{array}$ \\
\hline Duration of surgery (In hours) & 3.62 & 3.19 \\
\hline $\begin{array}{l}\text { Duration of hospital stay (In } \\
\text { days) }\end{array}$ & 4.12 & 3.67 \\
\hline Ambulation period (In days) & 1.46 & 1.62 \\
\hline $\begin{array}{l}\text { Oral liquid consumption (In } \\
\text { days) }\end{array}$ & 1.29 & 1.08 \\
\hline $\begin{array}{l}\text { [Table/Fig-6]: Comparison of various durations between laparoscopic Nissen's } \\
\text { and laparoscopic Toupet's fundoplication. }\end{array}$
\end{tabular}

\begin{tabular}{|c|c|c|c|c|}
\hline \multirow[b]{2}{*}{ Incidence } & \multicolumn{2}{|c|}{ At $3^{\text {rd }}$ month } & \multicolumn{2}{|c|}{ At $6^{\text {th }}$ month } \\
\hline & $\begin{array}{l}\text { Laparoscopic } \\
\text { nissen's }\end{array}$ & $\begin{array}{l}\text { Laparoscopic } \\
\text { toupet's }\end{array}$ & $\begin{array}{l}\text { Laparoscopic } \\
\text { nissen's }\end{array}$ & $\begin{array}{l}\text { Laparoscopic } \\
\text { toupet's }\end{array}$ \\
\hline Grade 0 & 15 (78.94\%) & 16 (94.12\%) & 17 (89.48\%) & 17 (100\%) \\
\hline Grade 1 & 02 (10.52\%) & 01 (5.88\%) & 01 (5.26\%) & - \\
\hline Grade 2 & 02 (10.52\%) & & 01 (5.26\%) & - \\
\hline Grade 3 & - & - & - & - \\
\hline
\end{tabular}

Symptoms like cough, hoarseness of voice, chest pain and asthma were observed in 8,3,12 and 7 cases respectively before surgery. Postoperatively, at the end of sixth month, only one case showed cough and one case had asthma. A study by Wang B et al., found no difference in the incidence of symptoms like dysphagia, heartburn and regurgitation between laparoscopic toupet's fundoplication and laparoscopic nissen's fundoplication [15]. The prevalence of postoperative dysphagia and gas related symptoms were comparatively higher in laparoscopic nissen's than laparoscopic toupet's group [16]. The postoperative recovery of acute dysphagia occurs immediately, mild dysphagia recovers within 6-8 weeks and chronic dysphagia recovers after $6-8$ weeks $[17,18]$.

Intraoperative complications like herniation and pneumothorax was observed in two cases each. The mean duration of surgery, duration of hospital stay and starting oral liquid consumption was comparatively higher in laparoscopic nissen's fundoplication than laparoscopic toupet's fundoplication. However, the average ambulation period of stay was less in laparoscopic nissen's than laparoscopic toupet's fundoplication. A study by Chrysos E et al., noticed prolonged operative duration in laparoscopic toupet's fundoplication $(90 \pm 12$ minutes) than laparoscopic nissen's fundoplication (67 \pm 15 minutes) [11]. Erenoglu $C$ et al., stated that the laparoscopic nissen's fundoplication and laparoscopic toupet's fundoplication was comparable in terms of operative duration, intraoperative blood loss, morbidity, length of hospitalisation, need for reoperation, and efficacy in terms of relieving symptoms. However, laparoscopic toupet's fundoplication was effective and safe procedure in the management of severe form of the GERD diseases [19].

A study by Wang B et al., stated that laparoscopic toupet's fundoplication was effective and safe on long-term use than laparoscopic nissen's fundoplication. However, laparoscopic toupet's fundoplication has lower incidence of postoperative dysphagia [15]. A study by Chrysos E et al., stated that laparoscopic toupet's fundoplication was associated with fewer functional symptoms, which was reduced and become similar with the laparoscopic nissen's fundoplication [11].

A study by Jose WH et al., stated that laparoscopic antireflux surgery is an effective treatment modality for the long-term management of GERD [20]. A study by Zoring C et al., stated that laparoscopic toupet's procedure is the better treatment modality, which has low rate of dysphagia and effective in controlling reflux than laparoscopic nissen's fundoplication [21]. A study by Su F et al., stated that laparoscopic nissen's fundoplication was better procedure than laparoscopic toupet's fundoplication in reducing the number of reflux episodes and decreasing postoperative dysphagia [22].

A study by Qin $M$ et al., stated that the incidence of dysphagia was significantly low in laparoscopic toupet's fundoplication and laparoscopic nissen's fundoplication may be optimal for moderate to severe GERD [12]. A study by Koch $\mathrm{OO}$ et al., stated that laparoscopic toupet's fundoplication and laparoscopic nissen's fundoplication are equally effective in the management of GERD and improving the quality of life of cases. However, the reoperation rate and dysphagia rate were lower and ability to belch was higher after laparoscopic toupet's fundoplication than laparoscopic nissen's fundoplication [23]. Marzia E et al., concluded that laparoscopic fundoplication is advisable only for those proton pump inhibitor (PPI) responsive GERD cases who develops complications [24]. In the present study, laparoscopic toupet's fundoplication and laparoscopic nissen's fundoplication were effective treatment modalities in the management of GERD. However, laparoscopic toupet's fundoplication is efficient in diminishing the incidence of the postoperative dysphagia than laparoscopic nissen's fundoplication [Table/Fig-7].

\section{Limitation(s)}

In view of limitations, the present study was non randomised with minimal sample size and with less postoperative follow-up period due to the Coronavirus Disease-2019 (COVID-19) pandemic crisis. Further, prospective evaluations needed to know the detailed impact of laparoscopic toupet's fundoplication and laparoscopic nissen's fundoplication in the management of GERD.

\section{CONCLUSION(S)}

The results of present study concluded that the laparoscopic toupet's fundoplication and laparoscopic nissen's fundoplication were comparable in the management of postoperative symptoms. The incidence of postoperative dysphagia was comparatively more in laparoscopic nissen's group than laparoscopic toupet's group. However, the incidence was diminished within six months of postoperative follow-up.

\section{REFERENCES}

[1] Richter JE. Gastroesophageal reflux disease in the older patient: Presentation treatment, and complications. Am J Gastroenterol. 2000;95(2):368-73.

[2] Agresta F, De Simone P, Leone L, Arezzo A, Biondi A, Bottero L. Italian Society Of Young Surgeons (SPIGC): Laparoscopic appendectomy in Italy: An appraisal of 26,863 cases. J Laparoendosc Adv Surg Tech A. 2004;14(1):01-08.

[3] El-Serag HB, Sweet S, Winchester CC, Dent J. Update on the epidemiology of gastro-oesophageal reflux disease: A systematic review. Gut. 2014;63(6):871-80.

[4] Bhatia SJ, Makharia GK, Abraham P, Bhat N, Kumar A, Reddy DN. Indian consensus on gastroesophageal reflux disease in adults: A position statement of the Indian Society of Gastroenterology. Indian J Gastroenterol. 2019;38(5):411-40.

[5] Salminen P. The laparoscopic Nissen fundoplication-a better operation? Surgeon. 2009; $7(4): 224-27$.

[6] Frazzoni M, Piccoli M, Conigliaro R, Frazzoni L, Melotti G. Laparoscopic fundoplication for gastroesophageal reflux disease. World J Gastroenterol. 2014;20(39):14272-79.

[7] Morais DJ, Lopes LR, Andreollo NA. Dysphagia after antireflux fundoplication: Endoscopic, radiological and manometric evaluation. Arq Bras Cir Dig. 2014;27(4):251-55.

[8] Ribeiro MC, Tercioti-Júnior V, Souza-Neto JC, Lopes LR, Morais DJ, Andreollo NA Identification of preoperative risk factors for persistent postoperative dysphagia after laparoscopic antireflux surgery. Arq Bras Cir Dig. 2013;26(3):165-69.

[9] Owers C, Ackroyd R. Management of gastroesophageal reflux disease and hiatus hernia: Overview and authors' perspective. J Surg. 2013;1(4):51-58. 
[10] Arivan R, Deepanjali S. Prevalence and risk factors of gastro-esophageal reflux disease among undergraduate medical students from a southern Indian medical school: a cross-sectional study. BMC Res Notes. 2018;11(1):448.

[11] Chrysos E, Tsiaoussis J, Zoras OJ, Athanasakis E, Mantides A, Katsamouris A. Laparoscopic surgery for gastroesophageal reflux disease patients with impaired esophageal peristalsis: Total or partial fundoplication? J Am Coll Surg. 2003;197(1):08-15.

[12] Qin M, Ding G, Yang H. A clinical comparison of laparoscopic Nissen and Toupet fundoplication for gastroesophageal reflux disease. J Laparoendosc Adv Surg Tech A. 2013;23(7):601-04.

[13] Liu S, Xu M, Yang J, Qi H, He F, Zhao X, et al. Research on gastroesophageal reflux disease based on dynamic features of ambulatory 24-hour esophageal ph monitoring. Computational and Mathematical Methods in Medicine. 2017:2017:9239074

[14] Genta RM, Spechler SJ, Kielhorn AF. The Los Angeles and Savary-Miller systems for grading esophagitis: Utilization and correlation with histology. Diseases of the Esophagus. 2011;24(1):10-17.

[15] Wang B, Zhang W, Liu S, Du Z, Shan C, Qiu M. A Chinese randomised prospective trial of floppy Nissen and Toupet fundoplication for gastroesophageal disease. Int J Surg. 2015;23(Pt. A):35-40.

[16] Granderath FA, Kamolz T, Granderath UM, Pointner R. Gas-related symptoms after laparoscopic 360 degrees Nissen or 270 degrees Toupet fundoplication in gastro oesophageal reflux disease patients with aerophagia as comorbidity. Dig Liver Dis. 2007;39(4):312-18.
[17] Wykypiel H, Bonatti H, Hinder RA, Glaser K, Wetscher GJ. The laparoscopic fundoplications: Nissen and partial posterior (Toupet) fundoplication. Eur Surg. 2006;38:244-49.

[18] Novitsky YW, Wong J, Kercher KW, Litwin DE, Swanstrom LL, Heniford BT. Severely disordered esophageal peristalsis is not a contraindication to laparoscopic Nissen fundoplication. Surg Endosc. 2007;21(6):950-54.

[19] Erenoglu C, Miller A, Schirmer B. Laparoscopic Toupet versus Nissen fundoplication for the treatment of gastroesophageal reflux disease. Int Surg. 2003;88(4):219-25.

[20] Jose WH, Sebastian V, Sorin M, Angel GSP, Esteban S. Long-term effectiveness of laparoscopic antireflux surgery as treatment of gastroesophageal reflux disease. retrospective analysis of a prospective database. Adv Res Gastroentero Hepatol. 2020;15(5):555925.

[21] Zornig C, Strate U, Fibbe C, Emmermann A, Layer P. Nissen vs toupet laparoscopic fundoplication. Surg Endosc. 2002;16(5):758-66.

[22] Su F, Zhang C, Ke L, Wang Z, Li Y. Efficacy comparison of laparoscopic Nissen, Toupet and Dor fundoplication in the treatment of hiatal hernia complicated with gastroesophageal reflux disease. Zhonghua wei Chang wai ke za zhi=Chinese Journal of Gastrointestinal Surgery. 2016;19(9):1014-20.

[23] Koch OO, Kaindlstorfer A, Antoniou SA, Luketina RR, Emmanuel K, Pointner R. Comparison of results from a randomised trial 1 year after laparoscopic Nissen and Toupet fundoplications. Surg Endosc. 2013;27(7):2383-90.

[24] Frazzoni M, Piccoli M, Conigliaro R, Frazzoni L, Melotti G. Laparoscopic fundoplication for gastroesophageal reflux disease. World J Gastroenterol. 2014;20(39):14272-79.

\section{PARTICULARS OF CONTRIBUTORS:}

1. Assistant Professor, Department of General Surgery, Government Medical College and Hospital, Nizamabad, Telangana, India.

2. Assistant Professor, Department of General Surgery, Government Medical College, Siddipet, Telangana, India.

\section{NAME, ADDRESS, E-MAIL ID OF THE CORRESPONDING AUTHOR:}

Abhishek Vodnala,

Assistant Professor, Department of General Surgery, Government Medical College,

Siddipet, Telangana, India.

E-mail: abhiv97@gmail.com
PLAGIARISM CHECKING METHODS: [Jain Het al.]

- Plagiarism X-checker: Oct 09, 2021

- Manual Googling: Oct 22, 2021

- iThenticate Software: Dec 09, 2021 (9\%)

\section{AUTHOR DECLARATION:}

- Financial or Other Competing Interests: None

- Was Ethics Committee Approval obtained for this study? Yes

- Was informed consent obtained from the subjects involved in the study? Yes

- For any images presented appropriate consent has been obtained from the subjects. NA

Date of Submission: Oct 08, 2021

Date of Peer Review: Nov 10, 2021

Date of Acceptance: Dec 14, 2021

Date of Publishing: Jan 01, 2022 